\title{
KONSEP PENDIDIKAN ISLAM
}

\section{DALAM PERSPEKTIF KIAI HAJI AHMAD DAHLAN}

\author{
Ahmad Isa Mubaroq \\ Aslich Maulana \\ Hasan Basri \\ Mohammad Ahyan Yusuf Sya'bani \\ Universitas Muhammadiyah Gresik \\ E-mail: Ahismu517@gmail.com
}

\begin{abstract}
Abstrak: Tujuan mendeskripsikan konsep pendidikan K.H Ahmad Dahlan. Metode penelitian yang digunakan adalah metode penelitian Library Research. Pengumpulan data dilakukan dengan cara mengumpulkan data-data yang berkaitan dengan konsep pendidikan K.H Ahmad Dahlan dari beberapa buku kemudian memberikan deskripsi lalu di simpulkan. Hasil pembahasan yang ditulis ini ada pertama konsep pendidikan menurut K.H Ahmad Dahlan menganggap yang menjadi target paling penting dalam tujuan pendidikan adalah pembentukan kepribadian. Kedua, tujuan pendidikan menurut K.H Ahmad Dahlan adalah Baik budi pekertinya, alim dalam agama, luas pengetahuan dalam ilmu dunia (umum), dan bersedia memperjuangkan kemajuan masyarakat. Ketiga, Model Pendidikan yang baik menurut K.H Ahmad Dahlan adalah pendidikan yang sesuai dengan kebutuhan masyarakat saat ini di mana peserta didik tersebut berada. Keempat, K.H Ahmad Dahlan melakukan pembaharuan pendidikan dengan cara memasukkan pelajaran agama di setiap sekolah umum
\end{abstract}

Kata Kunci: pendidikan Islam, ahmad dahlan 


\section{PENDAHULUAN}

$\mathrm{P}$ endidikan di Indonesia menjadi cita-cita ideal yang diharapkan oleh seluruh masyarakat.. Keberhasilan pendidikan tidak hanya ditinjau dari aspek nilai akademis dari kegiatan ujian saja, tetapi lebih jauh dan hasil dari kegiatan pendidikan harus mampu menjadi berbagai aspek kebutuhan masyarakat, terutama aspek moralitas bangsa.

Pendidikan agama Islam adalah " usaha sadar untuk menyiapkan peserta didik dalam meyakini, memahami dan mengamalkan agama Islam melalui kegiatan, bimbingan, pengajaran dan latihan ${ }^{1}$. Pendidikan merupakan 'barang penting' dalam komunitas sosial. Nabi Adam A.S yang memulai kehidupan baru di Jagad raya ini senantiasa dibekali akal untuk memahami setiap yang ia temukan dan kemudian menjadikannya sebagai pegangan hidup ${ }^{2}$. Oleh karena itu pendidikan Islam merupakan kebutuhan yang esensial dan fundamental, yang dibutuhkan oleh setiap muslim sepanjang hidup.

Pendidikan agama Islam sebagai dari tugas kita sebagai umat Islam yang mampu dan berpengetahuan luas untuk diajarkan

\footnotetext{
${ }^{1}$ Abdurahman Saleh, Pendidikan Agama Islam dan Keagamaan (Jakarta : Gamarindu panca Perkasa, 20000, Hal 37

2 Ahmad bazili dalam A.Malik Fadjar, Holistika Pemikiran Pendidikan (Jakarta: PT. Raha Grafindo Persada, 2005), Hal 5.
}

dan yang harus direalisasikan dalam hidup dan kehidupan.

Islam sebagai agama universal mengajarkan kepada umat manusia untuk melaksanakan pendidikan. Itu karena menurut ajaran Islam pendidikan merupakan kebutuhan hidup manusia yang mutlak harus dipenuhi. Dengan pendidikan manusia bisa menemukan arti untuk apa dia hidup, karena manusia dibekali akal dan struktur jasmani yang sempurna, dan hati nurani untuk merefleksikan diri dalam pengabdian kepada Allah SWT. Maka pendidikan yang diberikan atau dipelajari harus dengan nilainilai kemanusiaan tolak ukur nilai- nilai kemanusiaan itu sendiri.

Pendidikan Islam bukan sekedar proses penanaman nilai-nilai moral untuk membentengi diri dari aksi negatif globalisasi. Tetapi yang paling terkenal sekarang adalah bagaimana nilai-nilai moral yang telah ditanamkan pendidikan Islam tersebut mampu berperan sebagai kekuatan pembebas $^{3}$. Secara ideal, pendidikan Islam bertujuan melahirkan pribadi seutuhnya. Dari itu, pendidikan Islam diarahkan untuk mengembangkan segenap potensi manusia, seperti; fisik, akal, ruh dan hati ${ }^{4}$.

\footnotetext{
${ }^{3}$ Mohammad Shofa, Pendidikan Berparadigma Profektif (Yogyakarta : IRCiSoD, 2004), Hal 5.

${ }^{4}$ Ibid, hal. 11
} 


\section{LANDASAN TEORI}

\section{Riwayat Kiai Haji Ahmad Dahlan}

KH Ahmad Dahlan lahir di Kampung Kauman, Yogyakarta pada tahun 1868 dan Meninggal pada Tanggal 23 Februari 1923 dengan nama Muhammad Darwis ${ }^{5}$. Ayahnya KH Abu Bakar bin Kiai Sulaiman adalah imam dan Khatib Masjid Besar Kauman Yogyakarta, sementara ibunya Siti Aminah adalah anak KH Ibrahim, penghulu besar di Yogyakarta ${ }^{6}$. Menurut salah satu silsilah, keluarga Muhammad Darwis dapat dihubungkan dengan Maulana Malik Ibrahim, salah seorang wali penyebar agama Islam yang telah dikenal di Pulau Jawa ${ }^{7}$. KH Ahmad Dahlan menyelesaikan pendidikan dasarnya pada Madrasah dan Pesantren di Yogyakarta dalam bidang nahwu, Fiqih, dan tafsir ${ }^{8}$. Pada tahun 1888, Ahmad Dahlan disuruh oleh orang tuanya menunaikan ibadah haji. Ia bermukim di Mekkah selama 5 Tahun untuk menuntut ilmu agama Islam, seperti qiraat, tauhid, tafsir, Fiqih, tasawuf, ilmu mantik, dan ilmu falaq ${ }^{9}$. Sepulang dari Makkah yang pertama ia telah mengganti namanya (dari Muhammad Darwis menjadi Haji Ahmad Dahlan) dan tak lama kemudian

${ }^{5}$ Ensiklopedi Islam, Dewan Redaksi Ensiklopedi Islam, (Cet.XI, Jakarta: PT Ichtiar Baru Van Hoeve, 2003) hal 83.

6 Abuddin Nata, Tokoh-tokoh Pembaharuan Pendidikan Islam di Indonesia, (Jakarta: PT Raja grafindo Persada, 2005) hal 98.

7 Sukardjo dan Ukim Komaruddin, Landasan Pendidikan; Konsep dan Aplikasinya, (Jakarta: PT Rajagrafindo Persada, 2009), hal 108. ia menikah dengan Siti Walidah putri Kyai Penghulu Haji Fadhil ${ }^{10}$.

Pada tahun 1903 ia berkesempatan kembali pergi ke Makkah untuk memperdalam ilmu agama selama 3 tahun $^{11}$. Kali ini ia banyak belajar dengan Syekh Ahmad Khatib Minangkabau. Di samping itu, ia juga tertarik pada pemikiran Ibnu Taimiyah, Jamaluddin al-Afgani, Muhammad Abduh dan Muhammad Rasyid Rida dan di antara kitab tafsir yang menarik hatinya adalah Tafsir al- Manar. Dari tafsir inilah beliau mendapatkan inspirasi dan motivasi untuk mengadakan perbaikan dan pembaruan umat Islam di Indonesia. Selama tinggal di kota Makkah, Ahmad Dahlan bertemu dengan ide-ide pembaharuan Islam yang dipelopori Jamaluddin Al- Afgani, Muhammad Abduh dan Rasyid Ridha ${ }^{12}$. Ahmad Dahlan bukanlah seorang penulis, sehingga gagasan-gagasan pemikirannya disampaikan secara lisan dan karya nyata ${ }^{13}$. Oleh karena itu ia dikenal sebagai pelaku dibandingkan sebagai pemikir. Sebelum mendirikan organisasi Muhammadiyah, Ahmad Dahlan menjadi tenaga pengajar agama di Kampungnya. Di samping itu ia

8 Djamaluddin dan Abdullah, Kapaita Selekta Pendidikan Islam, (Cet.II, Bandung: CV Pustaka Setia, 1999), hal 89.

${ }^{9}$ Ensiklopedi Islam, Op.Cit., hal 83.

10 Amir Hamsyah, Pembaharuan Pendidikan dan Pengajaran Islam, (Malang: UP Kenmutia, 1968), hal. 70

${ }^{11}$ Ensiklopedi Islam, Op.Cit., hal. 83.

${ }^{12}$ Abuddin Nata, Op.Cit., hal 99

${ }^{13}$ Ibid., hal 99 
juga mengajar disekolah negeri, seperti sekolah Kweekschool (sekolah raja) di Jetis (Yogyakarta) dan Opleiding School voor Inlandsche Ambtenaren (OSVIA, Sekolah Pendidikan untuk Pegawai Pribumi) di Magelang ${ }^{14}$. Sambil mengajar ia juga berdagang dan bertablig.

Sementara itu, sesuai dengan ide-ide pembaruan yang ia serap dari pemikiran Ibnu Taimiyah, al-Afgani, Abduh dan Rasyid Rida, ia pun memulai melakukan usaha-usaha meluruskan Aqidah dan amal ibadah masyarakat Islam di Kauman ${ }^{15}$. Usaha yang ia lakukan adalah mendirikan surau dengan kiblat yang benar. Menurut pandangan KH Ahmad Dahlan, sesuai ilmu yang ia miliki, banyak tempat ibadah yang tidak benar arah kiblatnya, di antaranya Masjid Agung Yogyakarta ${ }^{16}$.

Dalam perjalanan perjuangannya, $\mathrm{KH}$ Ahmad Dahlan sering melakukan hal-hal yang menurut ukuran ulama waktu itu tidak sejalan dengan ajaran Islam, seperti memberi pengajian kepada kaum muslimat, dan membolehkan wanita keluar rumah selain untuk mengaji ${ }^{17}$. Dakwah yang disampaikan Ahmad Dahlan tidak hanya terbatas pada masyarakat awam, melainkan juga kepada pegawai golongan atas. Dalam konteks pergerakan sosial- keagamaan,

\footnotetext{
${ }^{14}$ Ensiklopedi Islam, Op.Cit., Hal 83.

${ }^{15}$ Sukardjo dan Ukim Komaruddin, Op.Cit., Hal 108.

${ }^{16}$ Ibid Hal 109.
}

budaya, dan kebangsaan, dapat diungkapkan dengan adanya interaksi personal maupun formal antara Ahmad Dahlan dengan organisasi, seperti: Budi Utomo, Sarikat Islam, dan Jamiat Khair, maupun hubungan formal antara organisasi yang ia cirikan kemudian, terutama dengan Budi Utomo ${ }^{18}$.

Setelah banyak mendengar tentang aktivitas dan tujuan organisasi Budi Utomo melalui pembicaraan pribadi dan kehadirannya dalam pertemuan- pertemuan resmi, Ahmad Dahlan kemudian secara resmi menjadi anggota Budi Utomo pada tahun $1909^{19}$. Dalam perkembangan selanjutnya, Ahmad Dahlan tidak hanya menjadi anggota biasa, melainkan ia menjadi pengurus Kauman dan salah seorang komisaris dalam kepengurusan Budi Utomo Cabang Yogyakarta. Sementara itu, pada sekitar tahun 1910 Ahmad Dahlan juga menjadi anggota Jamiat Khair, organisasi Islam yang banyak bergerak dalam bidang pendidikan dan mayoritas anggotanya adalah orang-orang Arab. Keterlibatan secara langsung di dalam Budi Utomo memberi pengetahuan yang banyak kepada Ahmad Dahlan tentang cara berorganisasi Dalam organisasi- organisasi yang diikuti Ahmad Dahlan mulai tertanam benih-benih ide yang ingin dia terapkan tentang ide-ide pembaharuan. Olehnya itu, dia pun merasa perlu untuk mendirikan

\footnotetext{
${ }^{17}$ Ensiklopedi Islam, Op.Cit., Hal 83.

${ }^{18}$ Sukardjo dan Ukim Komaruddin, Op.Cit., Hal109.

${ }^{19}$ Ibid Hal 110.
} 
wadah dalam bentuk organisasi untuk menghimpun orang-orang yang seide dengan dia. Akhirnya, atas dorongan muridmuridnya serta teman-temannya, pada Tanggal 18 November 1912 (8 Zulhijjah 1330), KH Ahmad Dahlan mendirikan Muhammadiyah $^{20}$. Selain dirinya sendiri, pengurusnya adalah Abdullah Siradj (Penghulu), Haji Ahmad, Haji Abdurrahman, R Haji Sarkawi, Haji Muhammad, R H Djaelani, Haji Anis, dan Haji Muhammad Fakih $^{21}$.

\section{Dasar Pemikiran K.H Ahmad Dahlan}

Hampir seluruh pemikiran Dahlan berangkat dari keprihatinannya terhadap situasi dan kondisi global umat Islam waktu itu yang tenggelam dalam kejumudan (stagnasi), kebodohan, serta keterbelakangan. Kondisi ini semakin diperparah dengan politik kolonial Belanda yang sangat merugikan.

Bangsa Indonesia. Latar belakang situasi dan kondisi tersebut telah mengilhami munculnya ide pembaharuan Dahlan. Ide ini sesungguhnya telah muncul sejak kunjungannya pertama ke Makkah. Kemudian ide tersebut lebih dimantapkan setelah kunjungannya yang kedua. Hal ini berarti, bahwa kedua kunjungannya merupakan

\footnotetext{
${ }^{20}$ Ensiklopedi Islam, Op.Cit., Hal 83.

${ }^{21}$ Ibid Hal 83.
}

proses awal terjadinya kontak intelektualnya baik secara langsung maupun tidak langsung dengan ide-ide pembaharuan yang terjadi di Timur Tengah pada awal abad XX .

\section{METODOLOGI PENELITIAN}

Penelitian merupakan langkah awal yang harus dilakukan dalam menyusun skripsi dan sesuatu yang berkaitan dengan pokok permasalahan diperlukan suatu pedoman atau metode penelitian, sehingga penelitian yang dilakukan dapat dipertanggungjawabkan kebenarannya. Untuk mendapatkan hasil penelitian yang baik, diperlukan metode yang baik dan dapat dipercaya. Dalam hal ini metode penelitian yang dimaksud adalah sebagai citra yang dipakai untuk memperoleh data-data yang dibutuhkan, serta cara mengelola data-data tersebut sehingga menjadi kesimpulan yang dapat diuraikan dalam analisis data ${ }^{22}$.

\section{Jenis Penelitian}

Sesuai dengan permasalahan dalam penelitian ini maka metode penelitian yang digunakan adalah penelitian pustaka (Library research). Penelitian pustaka adalah suatu penelitian menjadikan bahan pustaka sebagai sumber data utama, sehingga lebih kepada dokumentasi

\footnotetext{
22 Mohammad Nazir, Metode Penelitian, Ghalia Indonesia, Jakarta, 1988, hal. 99
} 
(documentation research) ${ }^{23}$. Langkah yang dilakukan adalah dengan cara meneliti dan menelaah buku - buku yang memuat tentang Konsep pemikiran Pendidikan Islam K.H Ahmad Dahlan.

\section{Pendekatan Penelitian}

Pendekatan penelitian ini penulis menggunakan pendekatan kualitatif. Pendekatan kualitatif adalah penelitian yang tidak menggunakan perhitungan ${ }^{24}$. Penelitian kualitatif dilakukan pada kondisi alamiah dan bersifat penemuan. Dalam penemuan kualitatif, peneliti adalah instrumen kunci. Oleh karena itu peneliti harus memiliki bakat teori dan wawasan yang luas jadi bisa bertanya, menganalisis dan mengonstruksi obyek yang diteliti menjadi lebih jelas. Penelitian ini lebih menekan pada makna yang terkait nilai.

Penelitian kualitatif digunakan juga masalah belum jelas, untuk mengetahui makna yang tersembunyi, untuk memahami interaksi sosial, untuk mengembangkan teori untuk memastikan kebenaran data, dan meneliti sejarah perkembangan ${ }^{25}$.

Dalam hal ini maka peneliti menganalisis makna konsep pendidikan Islam profetik K.H Ahmad Dahlan.

\footnotetext{
23 Sugiyono, Memahami Penelitian Kualitatif, Alfabeta, Bandung, 2005, hal. 15

${ }^{24}$ Lexy J. Moleong, Metodologi Penelitian Kualitatif, Remaja Rosda Karya, Bandung, 1999,
}

\section{Sumber Data}

Sesuai dengan jenis penelitian yang digunakan dalam penelitian maka teknik pengumpulan data yang tepat adalah dengan mengumpulkan buku-buku makalah, artikel, majalah, jurnal, dan lain sebagainya. Langkah ini biasanya dikenal dengan metode dokumentasi. Suharsimi, berpendapat bahwa metode dokumentasi adalah mencari data mengenai hal-hal atau variabel yang berupa catatan, transkrip, surat kabar, majalah prasasti notulen rapat, leger, agenda dan sebagainya.

Teknik ini digunakan oleh penulis dalam mengumpulkan data yang membahas tentang konsep pendidikan Islam profetik K.H Ahmad Dahlan dan sumber yang relevan dengan objek kajian Metode pengolahan data ada dua tahap yang penulis lakukan dalam metode pengolahan data ini, yaitu tahap pertama mengidentifikasikan suatu data kemudian dikorelasikan dengan buku referensi, setelah data terkumpul, langkah selanjutnya adalah menganalisis isi (Content analysis), yaitu dengan mengategorikan teori-teori dan data suatu informasi yang didapat dari rujukan-rujukan terlebih dahulu, kemudian akan dipilih dengan sistematis, digeneralisasikan dan kemudian

\footnotetext{
${ }^{25}$ Masrukhin, Metodologi Penelitian Kualitatif, Media Ilmu Press, Kudus, 2015, hal. 15
} 
ditarik sebuah benang merah yang dapat merumuskan semua itu secara lugas.

\section{HASIL DAN PEMBAHASAN}

\section{Pemikiran Pendidikan Agama Islam}

\section{K.H Ahmad Dahlan.}

K.H Ahmad Dahlan merupakan tokoh nasional yang memiliki tipe man of action artinya K.H Ahmad Dahlan lebih menonjol ke urusan masalah praktik maka dari ini warisan dari K.H Ahmad Dahlan lebih condong ke kegiatan-kegiatan di luar kelas yang lebih banyak ke teori, sehingga ia tidak banyak memiliki karya tulisan. Cita- cita pendidikan yang digagas oleh K.H Ahmad Dahlan adalah lahirnya manusia- manusia baru yang mampu tampil sebagai "intelektual-ulama", yaitu seorang muslim yang memiliki keteguhan iman dan berpikiran luas $^{26}$. Maka dari itu, ide pendidikan yang digagas K.H Ahmad Dahlan menyelamatkan umat Islam dari cara berpikir statis menuju pemikiran yang dinamis, kreatif dan inovatif, itu merupakan satu-satunya jalan mencapai tujuan tersebut dan melalui pendidikan dan pengolahan pendidikan agama Islam secara modern dan profesional, sehingga pendidikan yang dilaksanakan mampu memenuhi atau menghadapi dinamika pada zamannya ${ }^{27}$.

\footnotetext{
26 Sutrisno Sutoyo, Kiai Haji Ahmad Dahlan dan persyarikatan Muhammadiyah (Jakarta: Depdikbud, 1985), Hal 24.
}

\section{Integrasi Ilmu Agama dan Ilmu Umum}

Menurut K.H Ahmad Dahlan, upaya untuk mencapai tujuan ini membutuhkan proses pendidikan bersifat integral. Artinya, peserta didik harus mempunyai kecerdasan yaitu intelektual, spiritual, emosional dan sosial. Dengan demikian, proses pendidikan akan mampu menghasilkan calon ulama yang berintelektual. Untuk menciptakan peserta didik yang demikian, pendidikan harus berimbang antara pengetahuan umum dan agama. Melalui pengetahuan umum peserta didik akan mengenal kehidupan yang bersosial, budaya dan ekonomi serta mencapai kehidupan yang baik di dunia dan akhirat karena A1-Qur'an dan As-Sunnah tidak membeda - bedakan antara ilmu agama dan ilmu umum.

Menurut Ahmad Dahlan, pendidikan yang baik adalah pendidikan yang sesuai dengan tuntunan zaman. seperti contoh, pada awal abad 20-an, Ahmad Dahlan melihat umat Muslim di Indonesia tertinggal secara ekonomi oleh kolonialisme Belanda. Ketika itu ekonomi Muslim sangat tidak mempunyai akses ke sektor-sektor pemerintahan atau perusahaan-perusahaan swasta. Karena partisipasi Muslim yang rendah terhadap sektor-sektor pemerintahan itu membuat

\footnotetext{
27 Al-Rasyid, Samsul Nizar, Pendekatan Historis, Teoritis dan Praktis Filsafat pendidikan Islam (Jakarta: Ciputat Press, 2005), Hal 108
} 
kebijakan pemerintahan kolonial Belanda menutup akses bagi Muslim untuk masuk. Peristiwa ini mendorong Ahmad Dahlan untuk memperbaiki dengan memberikan pencerah tentang pentingnya pendidikan yang sesuai dengan perkembangan zaman ${ }^{28}$.

\section{Kebebasan untuk Berpikir}

Bahwa penyebab utama kemunduran umat Islam disebabkan pola pikir yang dimiliki dan cara pandang terhadap masa yang akan datang, sehingga pada masa tersebut umat Islam tertinggal jauh dengan umat yang lain. Oleh karena itu, kebebasan berpikirlah menjadikan atribut penting yang menjadikan manusia sebagai pedoman dalam perbuatan dan sedangkan kemauanlah yang menjadi pendorong perbuatan manusia. Artinya kebebasan berpikir merupakan upaya untuk mencapai pengetahuan. Dengan pengetahuan itu manusia menjadi lebih mampu dan mengerti untuk melanjutkan tugas kekhalifahannya di bumi serta mampu memosisikan dirinya lebih baik di antara makhluk-makhluk lainnya. Oleh karena itu, carilah ilmu dan berpikirlah untuk mengenal segala hal yang baik dan buruk untuk dirinya.

Menurut Ahmad Dahlan, menjadi manusia menuju kepada kebebasan berpikir

28 Abuddin Nata, Tokoh-Tokoh Pembaruan Pendidikan Islam di Indonesia. Hal 102-103. memang berarti progresif dan dinamis, akan tetapi kebebasan itu seharusnya bersifat relatif, terikat oleh ruang dan waktu, karena yang modern secara mutlak hanyalah Allah dan tetap berdasarkan dengan kaidah-kaidah ajaran Islam ${ }^{29}$. Pada tahun 1918, di sekolah Muhammadiyah yaitu Mulo met de Qur'an Ahmad Dahlan memasukkan pelajaran bahasa Arab sebagai mata pelajaran wajib, yang bertujuan peserta didik mampu untuk memahami arti dan makna Al- Qur'an dan Hadits secara ilmiah sehingga peserta didik itu sendiri tidak hanya sekedar ikut dan terhanyut pada pendapat orang lain. Dengan demikian, para peserta didik diharapkan mampu memperoleh kemampuan untuk memahami maksud dan arti dari Al-Qur'an dan Hadist.

\section{Pembentukan Karakter}

Pendidikan juga tidak cukup hanya sekedar kecerdasan intelektual, tetapi pembentukan karakter sangat penting pada peserta didik di kehidupan sehari- harinya. Maka dari itu melalui pendidikan para peserta didik dapat memenuhi kepribadian yang utuh baik jasmani maupun rohani dan memiliki jiwa sosial yang baik juga. Ahmad Dahlan sendiri menekankan pembentukan karakter harus diawali dengan iman, ilmu dan amal. Karena setiap perbuatan yang

\footnotetext{
29 Toto Suharto, Filsafat Pendidikan Islam (Yogyakarta : ar-Ruzz Media, 2011) Hal 307.
} 
dilakukan dengan tujuan baik, kepercayaan diri dan ikhlas maka Allah akan memberikan kemudahan pada perbuatannya. Dengan adanya ilmu yang kita miliki, setiap manusia wajib mengamalkan ilmunya, ilmu dan amal adalah dasar dari pendidikan pembentukan karakter yang diterapkan oleh Ahmad Dahlan.

Sebagaimana pada tahun 1910 Ahmad Dahlan pernah mengajarkan pendidikan agama Islam kepada para calon guru di Kweekschool Yogyakarta. Ia berharap bahwa pendidikan para calon guru diharapkan dapat mempercepat proses transmisi ide-ide yang di gagas oleh Ahmad Dahlan, karena mereka setelah menjadi guru akan mempunya peserta didik yang banyak dan mengajarkannya kepada peserta didik. Selain itu para guru kelak akan menjadi orang yang mempunyai pengaruh luas dan besar kepada peserta $\operatorname{didik}^{30}$. Maksudnya peserta didik akan mempunyai akhlak yang baik tergantung pada pendidik yang mendidiknya.

\section{KESIMPULAN}

1. Pada awal abad ke 20 konsep pemikiran K.H Ahmad Dahlan dalam bidang pendidikan sangat bertolak belakang dengan konsep pendidikan pemerintahan kolonial

\footnotetext{
${ }^{30}$ Ridjaluddin F.N, Filsafat Pendidikan Islam: Pandangan K.H Ahmad Dahlan dan Beberapa
}

Belanda yang lebih mementingkan ilmu pengetahuan umum sementara lembaga pesantren lebih mementingkan ilmu agama. Hal tersebut berdampak pada pemikiran para orang tua yang beranggapan bahwa jika anaknya di sekolah pemerintah Hidia Belanda dianggaplah seorang kafir. Sementara jika anaknya dimasukkan ke pesantren, anak tersebut kurang mempunyai ilmu pengetahuan umum yang cukup.

2. Keadaan tersebut ditanggapi oleh K.H Ahmad Dahlan bahwa umat Muslim tidak dapat berpikir secara monoton atau memisahkan diri dari mempelajari pengetahuan umum dan agama. Oleh karena itu K.H Ahmad Dahlan berupaya mencari solusi dengan mendirikan sekolah melalui organisasi Muhammadiyah yang mengolaborasikan antara pendidikan agama dan pengetahuan umum. Melalui Pendidikan yang diajarkan K.H Ahmad Dahlan mempunyai harapan para peserta didik dapat mempunya kelebihan dalam segala bidang ilmu pengetahuan.

3. Adapun kurikulum yang diterapkan pada sekolah yang didirikan oleh Muhammadiyah meliputi integrasi ilmu dan amal. Artinya peserta didik harus menuntut ilmu setinggi- tingginya agar dapat mengamalkan ilmunya orang lain, karena dalam ajaran Islam dianjurkan seorang Muslim harus

Tokoh Lainnya, Pemecahan Problem Pendidikan Bangsa, Hal 505. 
mempraktikkan ilmu tersebut, yang berarti berkarya sebagai contoh K.H Ahmad Dahlan membuat panti asuhan Hoofdbestur pada tahun 1921, agar anak yatim/piatu dapat terhindar dari kebodohan dimasa penjajahan kolonial Belanda dan juga membuat organisasi Aisyiyah (Khusus wanita) pada tahun 1917, agar seorang wanita juga harus berpendidikan tinggi dikarenakan pendidikan seorang anak dimulai dari pendidikan rumah dengan seorang ibu.

4. Integrasi ilmu agama dan ilmu umum. Artinya ilmu harus seimbang dan selaras agar peserta didik menjadi ulama yang berintelektual. Maka dari itu juga melalui Muhammadiyah K.H Ahmad Dahlan mendirikan sekolah-sekolah bercorak kolonial Belanda yang mengolaborasikan dengan ilmu agama dengan ilmu umum. Dengan demikian, ia berharap peserta didik mempunyai kelebihan dalam segala aspek bidang ilmu pengetahuan.

5. Kebebasan berpikir. Menurut K.H Ahmad Dahlan dengan adanya kebebasan berpikir peserta didik agar mampu mempunyai pendapat pribadi dari pemikirannya tersebut artinya peserta didik mampu mengembangkan, menjelaskan dan menjabarkan ajaran atau teori yang diajarkan oleh pendidik, dengan metode ini pendidik memberikan kesempatan pada peserta didik untuk berpikir secara modern, tetapi tidak menyimpang dari norma-norma agama yang telah dipelajari. Memberikan kebebasan berpikir

\section{DAFTAR PUSTAKA}

Abdullah, D. d. (1999). Kapita Selekta Pendidikan Islam. Bandung: CV Pustaka Setia. Barizi, A. (2005). Holistika Pemikiran Pendidikan. Jakarta: PT. Raja Grafindo Persada. Hamsyah, A. (1968). Pembaharuan Pendidikan dan Pengajaran Islam. Malang: UP Kenmutia.

Islam, Ensiklopedi. (2003). Dewan Redaksi Ensiklopedi Islam, Cet.XI. Jakarta: PT Ichtiar Baru Van Hoeve.

J. Moleong, L. (1995). Metodologi Penelitian Kualitatif. Bandung: Rosda Karya.

Komaruddin, S. d. (2009). Landasan Pendidikan; Konsep dan Aplikasinya. Jakarta: PT Raja Grafindo Persada.

Masud, A. (2001). Paradigma Pendidikan Islam. Yogyakarta: Pustaka Pelajar. Mulkan, A. M. (1993). paradigma Intelektual Muslim. Yogyakarta: Sipress.

Nata, A. (2005). Tokoh-Tokoh Pembaharuan Islam di Indonesia. Jakarta: PT Raja Grafindo Persada. Saleh, A. (2000). Pendidikan Agama dan 
Ahmad Isa Mubaroq, dkk - Konsep Pendidikan Islam...

Keagamaan. Jakarta: Gemarindu Pance Perkasa.

Shofan, M. (2004). Pendidikan Berparadigma Profetik. Yogyakarta: IRCiSoD.

Lihat Rubrik Bingkai pada suara Muhammadiyah edisi 24/TH.Ke-94 1631 Desember 2009. Sukardjo Muhammad \& Komarudin Ukim 2009, Landasan Pendidikan Konsep dan Aplikasinya. Munir Abdul (1990), Pemikiran K.H Ahmad Dahlan dan Muhammadiyah, Jakarta: Bumi Aksara.

Sutoyo Sutrisno, (1985) Kiai Haji Ahmad Dahlan dan persyarikatan Muhammadiyah Jakarta: Depdikbud

Nizar Samsul dan Al Rasyid, (2005) Pendekatan Historis, Teoritis dan Praktis Filsafat pendidikan Islam. Jakarta: Ciputat Press

Djamas Nurhayati, (2009) Dinamika Pendidikan di Indonesia Pasca Kemerdekaan Jakarta: PT Raha Grafindo Persada

Hadjid,(2004) Ajaran K.H Ahmad Dahlan dengan 17 Kelompok Ayat-Ayat AlQur'an Semarang PWM Jawa Tengah
Syuja,(2010) Islam Berkemajuan, Kisah Perjuangan K.H Ahmad Dahlan dan Muhammadiyah Masa Awal Tangerang: Al - Wasath

Sustrisno Kutoyo, Kiai Haji Ahmad Dahlan dan Persyarikatan Muhammadiyah

Rijaluddin F.N,(2009) Filsafat Pendidikan Islam: Pandangan K.H Ahmad Dahlan dan Beberapa Tokoh Lainya, Pemecahan Problem Pendidikan Bangsa Jakarta : Pustaka Kajian Islam FAI UHAMKA Sudarno Shobron,(2008) Studi Kemuhammadiyahan kajian Historis, Ideologis dan Organisasi. Surakarta: LPID

Sucipto Hery ,2010) K.H Ahmad Dahlan Sang Pencerah, Pendidikan dan Pendiri Muhammadiyah. Jakarta: Best Media Utama

Suharto Toto,(2011) Filsafat Pendidikan Islam Yogyakarta: ar-Ruzz Media Karel A.(1968) Steenbrink, Pesantren, Madrasah, Sekolah (Jakarta: LP3ES) 
Jurnal TAMADDUN-FAI UMG. Vol. XX. No.2 / Juli 2019 